Atmos. Chem. Phys., 3, 325-334, 2003

www.atmos-chem-phys.org/acp/3/325/

(6)

\title{
Emission of ions and charged soot particles by aircraft engines
}

\author{
A. Sorokin ${ }^{1}$, X. Vancassel $^{2}$, and P. Mirabel ${ }^{2}$ \\ ${ }^{1}$ Central Institute of Aviation Motors, 2 Aviamotornaya str., 111116, Moscow, Russia \\ ${ }^{2}$ Centre de Géochimie de la Surface, CNRS and Université Louis Pasteur 1, rue Blessig, F-67084 Strasbourg France
}

Received: 5 September 2002 - Published in Atmos. Chem. Phys. Discuss.: 13 November 2002

Revised: 6 March 2003 - Accepted: 10 March 2003 - Published: 27 March 2003

\begin{abstract}
In this article, a model which examines the formation and evolution of chemiions in an aircraft engine is proposed. This model which includes chemiionisation, electron thermo-emission, electron attachment to soot particles and to neutral molecules, electron-ion and ion- ion recombination, ion-soot interaction, allows the determination of the ion concentration at the exit of the combustor and at the nozzle exit of the engine. It also allows the determination of the charge of the soot particles. For the engine considered, the upper limit for the ion emission index $E I_{i}$ is of the order of $(2-5) \times 10^{16}$ ions $/ \mathrm{kg}$-fuel if ion-soot interactions are ignored and the introduction of ion-soot interactions lead about to a $50 \%$ reduction. The results also show that most of the soot particles are either positively or negatively charged, the remaining neutral particles representing approximately $20 \%$ of the total particles. A comparison of the model results with the available ground-based experimental data obtained on the ATTAS research aircraft engines during the SULFUR experiments (Schumann, 2002) shows an excellent agreement.
\end{abstract}

\section{Introduction}

Chemiions (CI) emitted from aircraft engines in exhaust plumes may play an essential role in aerosol formation. They are thought to act as condensation centres and then to promote the formation of volatile aerosols, but they are also invoked in the coagulation of the newly formed particles, where their presence will enhance coagulation and then will lead to particles larger than in the absence of charges (Frenzel and Arnold, 1994; Yu and Turco, 1997; Yu and Turco, 1998). However, to play this important role, CI must be present at rather high number densities and one of the key points is to know what the initial concentrations are, both

Correspondence to: P. Mirabel

(mirabel@illite.u-strasbg.fr) for positive and negative ions, at the level of the nozzle exit of an aircraft engine. However, only a few direct measurements at ground level are available, which show that the total $\mathrm{CI}^{-}$number densities are of the order of $10^{6}-10^{8} \mathrm{~cm}^{-3}$ for plume ages shorter than $1 \mathrm{~s}$ (Arnold et al., 1998; Sorokin and Mirabel, 2001). In addition to CI, soot particles are also emitted which may act as a sink for some of the CI, leading to the formation of charged soot particles (in addition to those formed directly by charged soot embryos). Neutral soot particles are generally invoked in the formation of contrails, but one can speculate that the presence of charged soot particles may intensify their role in contrail formation and evolution.

If chemi-ion formation in aircraft engine has not been studied extensively (see for example Strarik et al., 2002), the production of $\mathrm{CI}$ in hydrocarbon flames has already been investigated in great detail and their concentrations, at pressures in the range 2-760 torr, were found to be of the order of $10^{9}-10^{12} \mathrm{~cm}^{-3}$ (see, for example, Fialkov, 1997, for an extensive review on ions in flames). It has been shown that one of the most important reactions of chemi-ionisation in flames leads to the formation of $\mathrm{CHO}^{+}$(Calcote, 1962; Green and Sugden, 1963) which is, with $\mathrm{C}_{3} \mathrm{H}_{3}^{+}$and $\mathrm{C}_{2} \mathrm{H}_{3} \mathrm{O}^{+}$the dominant ion in the flame front of hydrocarbon fuels (Eraslan and Brown, 1988; Pederson and Brown, 1993; Calcote and Keil, 1990; Fialkov, 1997). These primary positive ions readily transfer their protons to substances having high proton affinity such as water, leading in most cases to hydronium ions $\mathrm{H}_{3} \mathrm{O}^{+}$, the most abundant positive ions in the oxidation zone after the flame front. The situation with negative ions is more complicated and non-unique. Two cases of dominance have been observed: electrons or negative ions and their concentration shares seem to depend strongly on the structure of the combustion zone and on the mixing ratio with air (Lawton and Weinberg, 1969; Goodings et al., 1979; Fialkov, 1997). Further reactions leading to the formation of the whole spectrum of negative ions are represented by electron attachment to neutral molecules, in accordance with their electron affini-

(C) European Geosciences Union 2003 
ties, and by numerous ion-molecule transfer reactions.

In laboratory flames the maximum rate of ion formation, produced mostly by chemi-ionization and then the maximum ion concentrations are observed near the zone of maximum temperature, i.e. in the flame front. Behind this reaction zone the ion concentration falls off quickly due to ion-ion recombination and ion attachment to soot particles. Soot particles themselves may be originally charged, especially if they are formed through the "ionic route", (Fialkov, 1997) but they may also gain a net charge through ion-attachment. Measurements indicate that in the hottest zone, soot particles may be charged according to equilibrium, (see, for example, Lawton and Weinberg, 1969) but this is not always the case and the initial particle charge seems to depend upon the material burnt (Burtscher et al., 1986). It is interesting to note that the net charge of soot particles in flames was found to be positive (Onischuk et al., 2001) even in the flame region where a large excess of electrons exists.

In the combustor of an aircraft engine, it is expected that CI are formed and interact with soot particles in the same way as in laboratory flames, however the whole spectrum of observed CI (both positive and negative) is much wider than in the case of laboratory flames (Kiendler et al., 2000a, b; Kiendler and Arnold, 2001). Nevertheless as for hydrocarbon flames in the post-flame region, the most abundant positive ions are still $\mathrm{H}_{3} \mathrm{O}^{+}$and some small hydrocarbon ions such as $\mathrm{C}_{3} \mathrm{H}_{3}^{+}$or $\mathrm{C}_{2} \mathrm{H}_{3} \mathrm{O}^{+}$, while the most abundant negative ions are $\mathrm{O}_{2}^{-}$and to a less extend $\mathrm{OH}^{-}, \mathrm{O}_{3}^{-}, \mathrm{CO}_{3}^{-}$, $\mathrm{NO}_{2}^{-}$or $\mathrm{NO}_{3}^{-}$and eventually some oxygenated hydrocarbon ions such as $\mathrm{C}_{\mathrm{x}} \mathrm{H}_{\mathrm{y}} \mathrm{O}_{\mathrm{z}}^{-}$(Fialkov, 1997; Kiendler et al., 2000b; Kiendler and Arnold, 2001).

The formation of soot particles and their partial oxidation in gas turbine combustors is a very complex process. Soot is produced mainly in the fuel-rich primary zone of the combustor, then oxidized in the high-temperature regions of the intermediate and dilution zones. Experimental measurements (IPCC, 1999) show that aircraft jet engines emit soot particles, which can be represented by a log-normal type size distribution peaking at about $20-30 \mathrm{~nm}$, with a number concentration at the nozzle exit which ranges between $10^{6}$ and $10^{7}$ particles per $\mathrm{cm}^{3}$.

As noted above, the charge of soot particles may have an impact on contrail formation and evolution. It may also have an impact on the emission levels of CI since the charging of soot includes ion-attachment to soot particles. In fact, the charging process of soot particles is a complex and not yet resolved problem. Soot particles can acquire their charges by thermoemission of electrons or by the capture of electrons, by interaction with CI (recombination or attachment), as well as by direct nucleation of charged soot "embryos". In a high-temperature zone (about 2000-2500 K), soot particles acquire a positive charge because of thermoionization. In contrast, if the temperature is not too high and if the concentration of free electrons is large, the capture of electrons by particles is the dominant process and particles may acquire a negative charge. In addition, the sign of the charges depends on the particle sizes; very small particles will favour positive charges while larger particles will be preferably negatively charged.

It is clear from the above examples, that the emission of $\mathrm{CI}$ as well as the charging of soot particles is strongly influenced by the temperature profile which itself depends on the structure of the air flow field in the engine and on mixing of fuel with air.

It is the purpose of this article to study the evolution of charged species, i.e. CI and soot particles in the combustor and post-combustor flow, in order to determine an upper limit for the ion number densities and to evaluate the charge distribution of soot particles at the nozzle exit of a typical aircraft engine.

\section{Methodology}

In a conventional engine, primary air is introduced through the dome or head-plate of the burner and through the first row of liner air holes (primary zone of combustor). To complete the combustion process and consume the unburned fuel, additional secondary air is introduced through a second row of lines holes. Finally dilution air is introduced in the dilution zone in order to carefully control exit temperature radial profiles to ensure acceptable turbine durability and performance (Lefebvre, 1985; Mattingly et al., 1987). In the primary zone the air-fuel ratio is less than unity and the temperature is not high enough to complete the fuel burning. It is in this primary zone that most of the soot (if not all) is generated. In the intermediate zone, location of the flame front, the air-fuel ratio is about one and complete fuel burning is achieved which brings the temperature to its highest level in the combustor. It is expected that the formation of chemiions proceeds mainly in this zone (which relative volume is small) leading to the highest CI concentrations (Lefebvre, 1985; Kuznetsov, 1983; Brocklehurst et al., 1997). In the dilution zone, the mean airfuel ratio is larger than unity. It is in this zone that soot particle charging is occurring, through interaction with positive and negative ions and through soot thermo-emission. Electrons attachment to oxygen molecules and ion-ion recombination are also taking place in this zone.

Based on these considerations, the following assumptions have been made:

- Since the formation of soot particle is an extremely complex problem, well beyond the scope of this study, we will assume that soot particles form only in the primary zone with a monodisperse size (diameter $=2 a$ ) and with an initial concentration equal to $N_{s}^{o}$.

- The primary charged species are mainly formed in the intermediate zone (flame front) with a rate production rate $Q(t)$. As discussed above, the primary charged 
negative species are electrons and the primary positive ions are $\mathrm{CHO}^{+}$(and may be also $\mathrm{CH}_{3}^{+}, \mathrm{C}_{3} \mathrm{H}_{3}^{+}$or $\mathrm{C}_{2} \mathrm{H}_{3} \mathrm{O}^{+}$), but the exact knowledge of the nature of positive ions is not mandatory in this approach. Due to the high temperature and high concentrations of primary ions, the charging of soot particles moving across the combustion zone is very effective.

- Further evolution of the different charged species in the dilution zone is represented by the electron attachment to soot particles and to neutral molecules, electron-ion and ion-ion recombination, ion-soot interaction (charged and neutral) and soot particles oxidation with partial coagulation (Calcote, 1962; Böhme, 1972, 2000; Fialkov, 1997).

2.1 Kinetic model of chemiions evolution and soot particles charging

Our model consists of four coupled differential equations which describe the time evolution of the concentrations of electrons $\left(n_{e}\right)$, negative $\left(n_{-}\right)$and positive $\left(n_{+}\right)$ions and soot particles $N$. These equations deal with the chemiionisation rate $Q(t)$ for the production of primary electrons and positive ions in the combustion zones, with soot particles charging (multi-charged particles are allowed) due to electron thermoemission $\left(J_{e, p}\right)$ or due to electron $\left(k_{e s}\right)$ or ion $\left(k_{i s, p}\right)$ attachment to soot particles, with electron-ion $\left(k_{e i}\right)$ and ionion $\left(k_{i i}\right)$ recombination and with electron attachment to neutral molecules $\left(k_{e a}\right)$. Soot particles oxidation in combustion and dilution zones as well as their mutual coagulation is neglected (see below).

$$
\begin{aligned}
& \frac{d n_{e}}{d t}=Q(t)+\Sigma J_{e, p} N_{s, p}-\Sigma n_{e} k_{e s, p} N_{s, p}-k_{e a} n_{e} n_{+} \\
& \quad-k_{e a} n_{e} \alpha_{a} A^{2}+D_{e} \\
& \frac{d n_{+}}{d t}=Q(t)-k_{e i} n_{e} n_{+}-k_{i i} n_{+} n_{-}-\Sigma n_{+} k_{i s, p} N_{s, p}+D_{i} \\
& \frac{d n_{-}}{d t}=k_{e a} n_{2} \alpha_{a} N^{2}-k_{i i} n_{+} n_{-}-\Sigma n_{-} k_{i s, p} N_{s, p}+D_{i} \\
& \frac{d N_{s, p}}{d t}=J_{e, p-1}-J_{e, p}-n_{e}\left(k_{e s, p} N_{s, p}-k_{e s, p+1} N_{s, p+1}\right) \\
& \quad-N_{s, p}\left(k_{i s, p} n_{-}+k_{i s, p} n_{+}\right)+k_{i s, p+1} n_{-} N_{s, p+1} \\
& \quad+k_{i s, p-1} n_{+} N_{s, p-1}+D_{s}
\end{aligned}
$$

In these equations, the coefficient $\alpha_{a}$ is the mole fraction of the neutral gas species to which the electrons will attach and $A$ is the total concentration of neutral molecules. The index $p$ in $k_{i s, p}$ or $N_{s, p}$ corresponds respectively to the attachment process described by Eqs. $(6 \mathrm{a}-\mathrm{c})$ or to the charges carried by soot particles ( $p=0, \pm 1, \pm 2$ etc. up to $\left.\pm p_{\max }\right)$. This system is solved taking into account the following initial conditions: $n_{e}=n_{-}=n_{+}=0$ and $N_{s, p}(p \neq 0)=0$ with $N_{s}^{o}=N_{s}(t=0)$. It also satisfies the conditions of conser- vation of the total concentration of particles and of electrical neutrality i.e.:

$$
\begin{aligned}
& N_{s}=\sum_{p} N_{s, p} \\
& n_{e}+n_{-}+\sum_{p<0}|p| N_{s, p}=n_{+}+\sum_{p>0} p N_{s, p}
\end{aligned}
$$

The maximum possible value for the charge $p$ in the model, $p_{\max }$, was chosen to be 13 . Finally, the term $D_{i}$ denotes the change in concentrations due to the exhaust expansion in the post-combustor flow or to the exhaust dilution in the plume. The numerical solution of the system of stiff kinetic equations was performed using the code DGEAR of the Fortran library IMSL.

We now rapidly examine each kinetic process involved in the equations.

\subsection{Chemiionisation rates in the combustion zone}

Chemi-ionisation rate is represented by the term $Q(t)$, the number of primary electrons or positive ions produced per unit of exhaust volume per second. A linear growth from zero to a maximum value $Q_{0}$ (corresponding to the position of the flame front) at time $\tau_{c}$ followed by a linear decrease to zero at time $2 \tau_{c}$ (just behind the combustion zone) is assumed. The values $\tau_{c}=10^{-6} \mathrm{~s}$ used in our calculations follows the assessment by Kuznetsov (1983) that the volume occupied by the intermediate zone is smaller than $1 \%$ of the total volume of combustion chamber. Test calculations made with our model show that the output results (e.g. at the combustor exit) are insensitive to the value of $\tau_{c}$ as long as $\tau_{c} \ll \tau_{\text {res }}$ where $\tau_{\text {res }}$ is the typical mean residence time of products in the combustion chamber (of the order milliseconds). The effect of pressure on the maximum rate of ion formation $Q_{0}$ was considered by Calcote (1962) for propane-air flames near-stoichiometry (equivalence ratio of 0.9 ) in a pressure range $33-760$ torr. The results indicate that this parameter depends on the pressure squared according to $Q_{0} / p^{2} \approx 5 \times 10^{9}$ ions s${ }^{-1} \mathrm{~cm}^{-3}$ torr $^{-2}$. In the present study we have used this dependence which considerably simplifies the analysis.

\subsection{Soot particles evolution}

As we already noted, soot formation and evolution processes are extremely complex. Soot is formed in the primary zone, but is oxidised in the regions downstream of the primary zone. The result of the oxidation is a decrease of the size or eventually the complete burning of the particles. Quantitatively accurate methods for calculating soot size distribution within an operating combustor have not yet been developed (Sudarev and Antonovsky, 1990; Brocklehurst et al., 1997; $\mathrm{Hu}$ et al., 2000). However, as will be shown later, it is possible to estimate the range of soot particle concentrations $N_{s}^{\circ}$ 
and mean size in aero-combustor, using the measurements of soot particles at the engine nozzle exit. Typical number concentrations at the nozzle exit range from $N_{s}^{\text {exp }}=10^{6}$ to $10^{7} \mathrm{~cm}^{-1}$ with diameters $d_{s} \approx 20-60 \mathrm{~nm}$ (IPCC, 1999). Behind the primary zone, the main change affecting soot particle number concentration and size is their mutual coagulation. For neutral particles, at the temperature considered $(T=1500-2000 \mathrm{~K})$, the coagulation coefficient $k_{i j}$ is of the order of $5 \times 10^{-9} \mathrm{~cm}^{3} \mathrm{~s}^{-1}$. For charged particles, this coagulation coefficient decreases for collisions of like charged and increases for collisions between oppositely charged particles. The coagulation coefficient $k_{i j}^{p q}$ for particles of radius $a_{i}$ and $a_{j}$ carrying $p$ and $q$ charges is given by (Seinfeld and Pandis, 1998):

$k_{i j}^{p q}=k_{i j} / W_{i j}^{p q}$

where $W_{i j}^{p q}$ is a correction factor given by:

$W_{i j}^{p q}=\frac{\exp (w)-1}{w}$,

with

$w=\frac{p q e^{2}}{\left(a_{i}+a_{j}\right) k T}$

where $e$ is the charge of the electron and $k$ is Boltzmann's constants. For $p=|q|=5$, the correction factor for opposite charges is of the order of $\left(1 / W_{i j}^{p q}\right) \leq 14$, leading to a coagulation coefficient of about $k_{i j} \leq 7 \times 10^{-8} \mathrm{~cm}^{3} \mathrm{~s}^{-1}$. This last value allows to determine the characteristic timescale for coagulation of soot particles in the combustor, behind the primary zone.

This characteristic timescale (time at which the initial concentration is divided by 2 ) is $2 / k_{i j} N_{s}^{\circ} \approx 100 \mathrm{~ms} \gg t_{\text {res }} \approx$ $1-10 \mathrm{~ms}$. The soot particle concentration may then be considered as approximately constant in the combustor, behind the primary zone. The evolution of their number concentration in the remaining part of the engine is then governed by the expansion of the exhaust gases in the turbine and in the nozzle. As a result, the soot concentration in the combustor, $N_{s}^{\circ}$, may be estimated by:

$N_{s}^{\circ} \approx N_{s}^{e x} \times \pi_{c} \times\left(T_{e x} / T_{c}\right)$

where $\pi_{c} \approx 20-40$ is a typical overall pressure ratio and where $T_{e x}(\approx 600-650 \mathrm{~K})$ and $T_{c}(\approx 1100-1600 \mathrm{~K})$ are respectively the temperature at the nozzle and combustor exit (Schumann et al., 2001). Thus, in the combustor the estimated soot particles concentration is of the order of $N_{s}^{\circ} \approx 7 \times 10^{6}-2 \times 10^{8} \mathrm{~cm}^{-3}$.

\subsection{Charging of soot particles}

Soot particles may lose or gain charges through electron thermo-emission, electron or ion attachment. The rate of electron thermo-emission $J_{e, p}$ from a soot surface depends on the temperature, on the charge and size of the soot particle (e.g. Ball and Howard, 1971):

$J_{e, p}=4 \pi a^{2} C T^{2} \exp \left(-W_{I} / k T\right)$

In this expression, $W_{I}=W+e^{2}(p+3 / 8) / a$ is the electron work function for a soot particle having a radius $a$ and carrying a charge $p, W$ is the work function of the bulk and $C$ is a constant given by:

$C=4 \pi m_{e} k^{2} / h^{3}=7.494 \times 10^{20} \mathrm{~cm}^{-2} \mathrm{~s}^{-1} \mathrm{~K}^{-2}$

where $m_{e}$ is the mass of the electron and $h$ is Plank's constant. For the bulk soot considered as graphite, $W=4.35 \mathrm{eV}$ (Lawton, 1968; Ball and Howard, 1971).

Following Natanson (1960) (see also Rapp, 2000), the capture rate $k_{i s, p}$ (or attachment coefficient) of a given ion $i$ (including electron) by particles in the nanometer size range is given by the following formulas (in units of $\mathrm{cm}^{3} / \mathrm{s}$ ), depending on whether or not the particle is neutral, carries the same charge than the ion or an opposite charge (the ion carry a single charge while soot particles carry $p$ charges). Formula $(6 a-c)$ apply respectively to the rate of attachment to neutral particle, rate of attachment with unlike charges and rate of attachment with like charges:

$$
\begin{aligned}
& k_{i s, o}=\pi a^{2} \bar{c}_{i}\left(1+\sqrt{\pi e^{2} / 2 k T a}\right) \\
& k_{i s, p}=\pi a^{2} \bar{c}_{i}\left[1+\frac{|p| e^{2}}{k T a}+\frac{16}{81} \frac{|p| e^{2}}{k T \lambda_{i}}\left(\frac{|p| e^{2}}{k T a}\right)^{2}\right] \\
& k_{i s, p}=\pi a^{2} \bar{c}_{i} g^{2} \exp \left[-\frac{|p| e^{2}}{g k T a}\left(1-\frac{1}{2 g\left(g^{2}-1\right)|p|}\right)\right]
\end{aligned}
$$

In these formula, $c_{i}$ is the mean thermal velocity of ion $i$, $\lambda$ is the mean free path of ions (or electrons). In Eq. (6c) the parameter $g=a_{o} / a$, where $a_{o}$ is the distance between the particle centre and the location where repulsive Coulomb force and attractive image force cancel (for more details, see Natanson, 1960; Hoppel and Frick, 1986).

\subsection{Electron-neutral molecules attachment rates}

The concentration of electrons in the burnt gases decays mainly by electron attachment to neutral molecules $\left(k_{e a}\right)$. It is obvious that $k_{e a}$ depends on the temperature and on the nature of the molecule to which the electron attach.

By analogy with the hydrocarbon fuel burning flames (e.g. Fialkov, 1997) it is reasonable to assume that the first negative ions are formed by three-body attachment of electrons to oxygen molecules:

$\mathrm{e}^{-}+\mathrm{O}_{2}+\mathrm{M} \geq \mathrm{O}_{2}^{-}+\mathrm{M}$

The reported forward rate coefficient adopted for this study (Gerhardt and Homann, 1990) is $k_{e a} \approx 1.4 \times$ 
$10^{-29}(300 / T) \exp (-600 / T) \mathrm{cm}^{6} / \mathrm{s}$. For the typical temperature range in the combustor $(T \approx 1500-2200 \mathrm{~K})$ this coefficient equals $k_{e a} \approx 1.7 \times 10^{-30} \mathrm{~cm}^{6} / \mathrm{s}$. Note, that at these high temperatures the reverse reaction of electron de-attachment may become noticeable (Kossyi et al., 1992), but the further transformations of $\mathrm{O}_{2}^{-}$to other negative ions is faster than this reverse reaction. Since in our model we cannot deal with the detail knowledge of the ionic species, these further transformations will be ignored.

\subsection{Electron-ion and ion-ion recombination}

Again, by analogy with hydrocarbon fuel burning flames, it is reasonable to consider $\mathrm{H}_{3} \mathrm{O}^{+}$as the dominant (secondary) positive ion downstream of the combustion zone. This ion is formed by the well known chemi-ionization reaction $\mathrm{CH}^{*}+\mathrm{O} \rightarrow \mathrm{HCO}^{+}+\mathrm{e}^{-}$, followed by proton transfer according to $\mathrm{HCO}^{+}+\mathrm{H}_{2} \mathrm{O} \rightarrow \mathrm{H}_{3} \mathrm{O}^{+}+\mathrm{CO}$ and $\mathrm{H}_{3} \mathrm{O}^{+}+\mathrm{e}^{-} \geq \mathrm{H}+\mathrm{H}+\mathrm{OH}$. In the present work we have used the value of the electron-ion recombination rate $k_{e i}$ measured by Guo and Goodings (2000) for $\mathrm{H}_{3} \mathrm{O}^{+} / \mathrm{e}^{-}$in $\mathrm{H}_{2}-\mathrm{O}_{2}-\mathrm{N}_{2}$ flames in a temperatures range $1820-2400 \mathrm{~K}$. The derived value is $k_{e i}=(0.0132 \pm 0.0004) \times T^{-1.37 \pm 0.05}$ leading to $4.6 \times 10^{-7} \mathrm{~cm}^{3} / \mathrm{s}$ at $1800 \mathrm{~K}$, a value very close to that reported by Butler and Hayhurst (1996), i.e. $5.2 \times 10^{-7} \mathrm{~cm}^{3} / \mathrm{s}$. These values are also very close to that concerning $\mathrm{NO}^{+}$, another major positive ion in the burnt gases, i.e. $4.2 \times 10^{-7} \mathrm{~cm}^{3} / \mathrm{s}$ at $2600 \mathrm{~K}$ (Hayhurst and Kittelson, 1978), leading to 5.04 at $1800 \mathrm{~K}$ if one assumes the theoretically expected temperature dependence $T^{-1 / 2}$ (Bates, 1950; Smirnov, 1983).

The ion-ion recombination rate $k_{i i},\left(\mathrm{~cm}^{3} \mathrm{~s}^{-1}\right)$ as will be shown below, is of major importance to determine the ion number concentration at the nozzle exit of an engine. Unfortunately, literature data on values of $k_{i i}$ are scarce, especially for the temperatures of interest. The theoretical analysis by Bates (1985) and the compilation of available data by Mätzing (1991) show that most of the recombination coefficients $k_{i i}$ for reactions $\mathrm{A}^{+}+\mathrm{B}^{-}+\mathrm{M} \rightarrow \mathrm{AB}+\mathrm{M}$ have a strong temperature dependence and may be represented by:

$k_{i i}(T)=a\left(\frac{300}{T}\right)^{0.5}+b[\mathrm{M}] \frac{P}{P_{0}}\left(\frac{300}{t}\right)^{n}$

where $n=3.5$ or 4 (Beig and Brasseur, 2000; Mätzing, 1991), $P$ and $P_{0}$ are net and standard pressure respectively and where $[\mathrm{M}]$ is the density of the third body in units of $\mathrm{cm}^{-3}$ (at $300 \mathrm{~K}$ and atmospheric pressure, $\mathrm{M} \approx 2.41 \times$ $10^{19} \mathrm{~cm}^{-3}$ ). This formula includes both the rates of bimolecular and termolecular neutralisation (e.g. Smith and Adams, 1982; Bates, 1982, 1985). Note that Eq. (8) includes already the variation of $[\mathrm{M}]$ with temperature.

Mätzing (1991) proposed the following values: $n=3.5$, $a=4 \times 10^{-7} \mathrm{~cm}^{3} \mathrm{~s}^{-1}$ and $b=3.0 \times 10^{-25}$ leading to $k_{i i}=9.22 \times 10^{-7}$ at $600 \mathrm{~K}$ and $1.77 \times 10^{-7} \mathrm{~cm}^{3} \mathrm{~s}^{-1}$ at $1800 \mathrm{~K}$ while Beig and Brasseur (2000) proposed $n=4$,

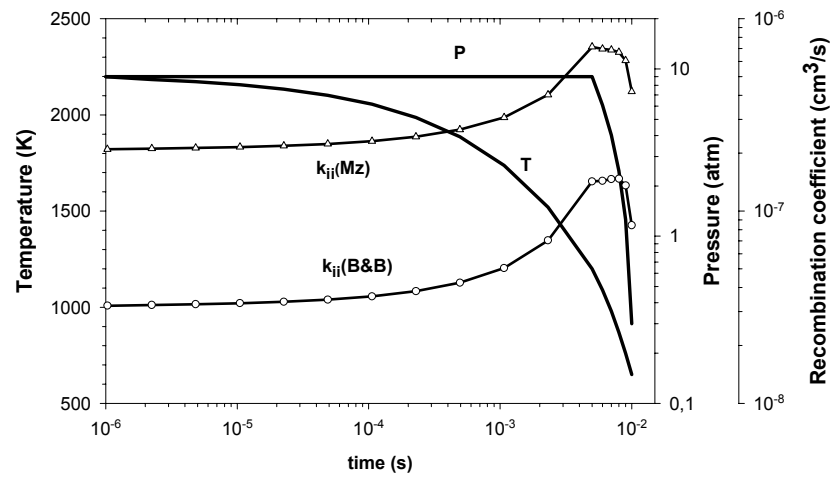

Fig. 1. Evolution of the temperature, pressure and ion-ion recombination coefficients $k_{i i}$ for the reference case. The indices $M_{z}$ and $B \& B$ refer to the compilation of Mätzing (1991) and of Beig and Brasseur (2000), respectively.

$a=6 \times 10^{-8} \mathrm{~cm}^{3} \mathrm{~s}^{-1}$ and $b=1.25 \times 10^{-25} \mathrm{~cm}^{6} \mathrm{~s}^{-1}$ leading to $k_{i i}=2.42 \times 10^{-7}$ at $600 \mathrm{~K}$ and $2.70 \times 10^{-8} \mathrm{~cm}^{3} \mathrm{~s}^{-1}$ at $1800 \mathrm{~K}$. These last values are about 4-7 times smaller than those given by Mätzing. Recently, Guo and Goodings (2000) have measured $k_{i i}$ as a function of temperature for $\mathrm{H}_{3} \mathrm{O}^{+}$ ions with $\mathrm{Cl}^{-}, \mathrm{Br}^{-}$and $\mathrm{I}^{-}$at flame temperatures (1820$2400 \mathrm{~K}$ ). The obtained values of $k_{i i}$ (calculated with their formulas), which are nearly independent of the ion pairs, lie between the predicted values of Mätzing and of Beig and Brasseur in the temperature range 1100-2000 K. In the present study, we will adopt the predictions of Mätzing as an upper limit for $k_{i i}$, and those of Beig and Brasseur as a lower limit in our temperature range. Note that in a previous study (Sorokin and Mirabel, 2001), we generated our own values of $k_{i i}$ for a temperature range $280-650 \mathrm{~K}$, but these values seem to be too high if extrapolated to higher temperatures. However, the concentrations calculated with this set of values are very closed to those calculated using the Mätzing's compilation.

\section{Results and discussion}

\subsection{Input parameters}

For the reference case, the model was run with the following parameters. In the combustor, the pressure $P_{c}$ is constant and given by $P_{c}=\pi_{c} P_{a}$ with an overall pressure ratio $\pi_{c}=30$, the temperature varied from $T=2200$ in the flame front to $T_{c}=1200 \mathrm{~K}$ at the combustor exit. The maximum chemiionisation rate (here $Q_{o}=10^{17} \mathrm{~cm}^{-3} \mathrm{~s}^{-1}$ ) takes place in the flame front located at $\tau_{c}=10^{-6} \mathrm{~s}$ and the total duration of the chemi-ionisation process is $2 \tau_{c}$. Finally, the residence time, passed the flame front is $5 \mathrm{~ms}$.

In the post-combustion zone, the temperature and pressure varied according to the simple law given by Tremmel and Schumann (1999), i.e. the temperature decreases lin- 


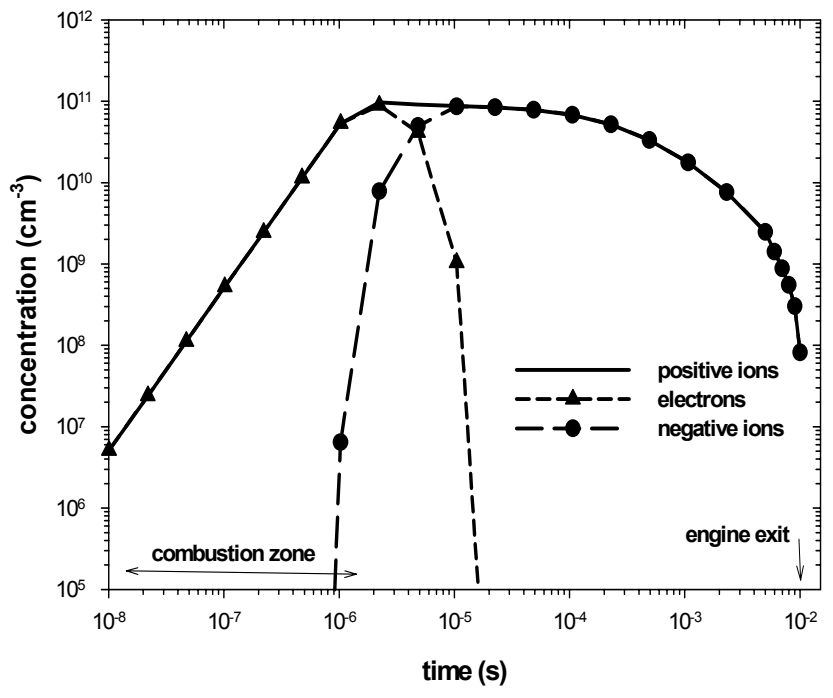

Fig. 2. Concentration profiles of the electrons, positive and negative ions in the engine for the reference case. The compilation of Beig and Brasseur (2000) has been used for the the ion-ion recombination coefficients $k_{i i}$.

early with time from $T_{c}=1200 \mathrm{~K}$ to $T_{e x}=650 \mathrm{~K}$ while the pressure varies as an hyperbolic function of time, between $P_{c}=9$ and $P_{a}=0.3 \mathrm{~atm}$., the ambient pressure. The mean residence time was taken as $5 \mathrm{~ms}$. The variation of $T, P$ and of $k_{i i}$, one of the most crucial parameter, as a function of time in the combustor and post-combustion zone are shown in Fig. 1.

\subsection{CI concentration in the absence of soot particles}

Let first consider the hypothetical case when no soot particles are present, i.e. when $N_{s}(t=0)=0$. This case will allow to assess an upper level for the CI concentrations at the nozzle exit and it will also show later, the influence of soot particles on this level. The results for $N_{s}=0$ are depicted in Fig. 2. As expected, the maximum of CI concentration (electrons and positive ions) is located just behind the flame front, at the end of the combustion zone. With $Q_{o}=10^{17} \mathrm{~cm}^{-3} \mathrm{~s}^{-1}$, the maximum ion concentration (for each sign) is of the order of $10^{11} \mathrm{~cm}^{-3}$. Just before this maximum, the primary electrons very rapidly attach to oxygen molecules, the most abundant neutral species with a large electronegativity. The electron concentration then decreases very steeply while at the same time the concentration of $\mathrm{O}_{2}^{-}$ also rises very steeply. The electron attachment rate to neutral molecules (using $A=3.7 \times 10^{19} \mathrm{~cm}^{-3}$ and the oxygen volume fraction $\left.\gamma_{\mathrm{O}_{2}}=0.15\right)$ is $k_{e a} \gamma_{\mathrm{O}_{2}} A^{2} \approx(3-7) 10^{8} \mathrm{~s}^{-1}$ i.e. the typical time for electron attachment to $\mathrm{O}_{2}$ molecules is of the order of $10^{-9} \mathrm{~s}$ which is much smaller than the residence time in the post-flame region and therefore in this region it can be assumed that $n_{-} \approx n_{+}=n_{i}$.

If furthermore we assume, for simplicity, the constancy of the ion-ion recombination coefficient, the ion concentration may be described by the simple equation $d n_{i} / d t=-k_{i i} n_{i}^{2}$ with the initial condition $n_{i}(t=0)=n_{i}^{o}$. The solution of this equation is:

$n_{i}(t) \approx \frac{n_{i}^{o}}{1+n_{i}^{o} k_{i i} t}$

In spite of its simple form, this solution shows some interesting features. In particular, it shows that if $n_{i}^{o} k_{i i} t \gg 1$, then the ion concentration is independent of the initial ion concentration, i.e. independent of $Q_{o}$ :

$n_{i}(t) \approx \frac{1}{k_{i i} t}$

This result is valid when the time exceeds a characteristic time scale, i.e. when $t>\tau_{i i} \approx 0.01 \mathrm{~ms}$ for $n_{i}^{o}=10^{12}$ and for $t>1 \mathrm{~ms}$ for $n_{i}^{o}=10^{10} \mathrm{~cm}^{-3}$, as it was observed in flames (Fialkov, 1997; Goodings et al., 1979). It is interesting to note that when this solution applies, the detailed information about the ions in the flame front is not needed if one is interested only by the total ion concentration $n_{c}$ at the exit of the combustor, because of the independence of $n_{i}(t)$ on $n_{i}^{o}$. At the combustor exit:

$n_{c}\left(\tau_{\text {res }}\right)=\left(k_{i i} \tau_{\text {res }}\right)^{-1}$

Using $\tau_{\text {res }}=5 \mathrm{~ms}$ and an average value of $k_{i i}=1.43 \times$ $10^{-7} \mathrm{~cm}^{3} \mathrm{~s}^{-1}$ (this value deduced from the formula of Beig and Brasseur for $T=1200 \mathrm{~K}$ and $P=9 \mathrm{~atm}$. represents a lower limit for $k_{i i}$ ), the maximum ion concentration of each sign at the combustor exit, calculated from Eq. (11), is about $1.4 \times 10^{9} \mathrm{~cm}^{-3}$. In fact, the use of the numerical model (Eq. 1) which takes into account the variation of $k_{i i}$ with $T$ and $P$ leads to $2.5 \times 10^{9} \mathrm{~cm}^{-3}$ at the combustor exit. During the further flow in the dilution zone, ion-ion recombination leads to additional decrease of the ion concentrations. However, this effect is small compared to the dominant effect of the expansion of the exhaust volume. Finally, one can get a good estimate of the upper level of the ion concentration $n_{e x}$ at the nozzle exit and of the emission index of ions $E I_{i}$ (number of ions per $\mathrm{kg}$ of fuel) by applying the simple law of exhaust expansion (see Eq. 4) combined with the ion concentration at the combustor exit:

$n_{e x} \approx \frac{n_{c} T_{c}}{T_{e x} \pi_{c}}=\frac{T_{c}}{k_{i i} \tau_{\mathrm{res}} T_{e x} \pi_{c}}$

and

$E I_{i} \approx \frac{T_{c} N_{f} R_{G}}{k_{i i} \tau_{\text {res }} \mu_{a} P_{a} \pi_{c}}$

where $N_{f}$ is the initial exhaust dilution ratio $\left(N_{f} \approx 70\right)$, $R_{G}$ is the gas constant and $\mu_{a}$ is the molecular weight of air ( $\left.\mu_{a}=29 \mathrm{~g} / \mathrm{mole}\right)$. It is interesting to note that these formula depends only on well-known parameters of the engine and on 


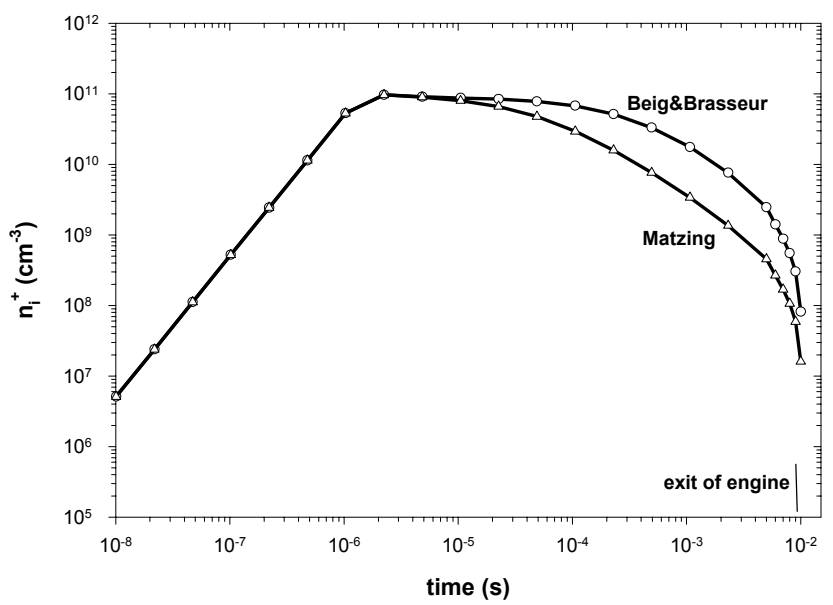

Fig. 3. Evolution of the concentration of positive ions in the engine for the reference case, using two approximations for the ion-ion recombination coefficients $k_{i i}$.

$k_{i i}$. For the conditions of our reference case and for $k_{i i}$ deduced from Beig and Brasseur, the maximum ion concentration of one sign at the nozzle exit and the maximum ion emission index are $n_{e x}=8.6 \times 10^{7} \mathrm{~cm}^{-3}$ and $E I_{i}=3.7 \times 10^{16}$. If the compilation of Mätzing (1991) is used, these values translate to $n_{e x}=1.72 \times 10^{7} \mathrm{~cm}^{-3}$ and $E I_{i}=0.74 \times 10^{16}$ (for $k_{i i}=7.13 \times 10^{-7} \mathrm{~cm}^{3} / \mathrm{s}$ ).

Figure 3 depicts the results given by the numerical model (Eq. 1) which takes into account the variation of $k_{i i}$ with temperature. The curves have been generated using the values of the two compilations for $k_{i i}$. If the compilation of Beig and Brasseur (2000) is used, $n_{e x}=8.2 \times 10^{7} \mathrm{~cm}^{-3}$ and this value represents probably an upper limit. If the compilation of Mätzing (1991) is used, $n_{e x}=1.6 \times 10^{7} \mathrm{~cm}^{-3}\left(n_{e x}\right.$ determined with the compilation of Sorokin and Mirabel, 2001 corresponds within $13 \%$ to that of Mätzing). It is interesting to note that the results given by the simplified model (Eqs. 11-12) are in good agreement with those provided by the numerical model.

Although approximate, Eqs. (9)-(12) give a good idea of the parameters which have a strong influence on $n_{e x}$, i.e. $k_{i i}$ and $n_{c}$ which itself depends upon $Q_{o}, \tau_{\mathrm{res}}, \pi_{c}, T_{c}$ and $T_{e x}$. The influence of $k_{i i}$ in the model results has already been discussed above, and we now examine the influence of $Q_{o}$. For this, the model was run with different values of $Q_{o}$ varying from $10^{15}$ to $10^{19} \mathrm{~cm}^{-3} \mathrm{~s}^{-1}$ and the results are shown in Fig. 4. This figure clearly shows, as predicted by Eq. (10), that for a sufficiently high chemiionisation rate $\left(Q_{o} \geq 10^{16} \mathrm{~cm}^{-3} \mathrm{~s}^{-1}\right)$ the ion-ion recombination process leads to an asymptotic behaviour for the ion concentrations at the combustor exit ( $t=5 \mathrm{~ms}$ ) and therefore the ion concentrations at the nozzle exit is independent of $Q_{o}$.

The model results confirm, as predicted by Eq. (12), the dependence of $n_{e x}$ on $\tau_{\mathrm{res}}, T_{c}, T_{e x}$ and $\pi_{c}$. For example, the

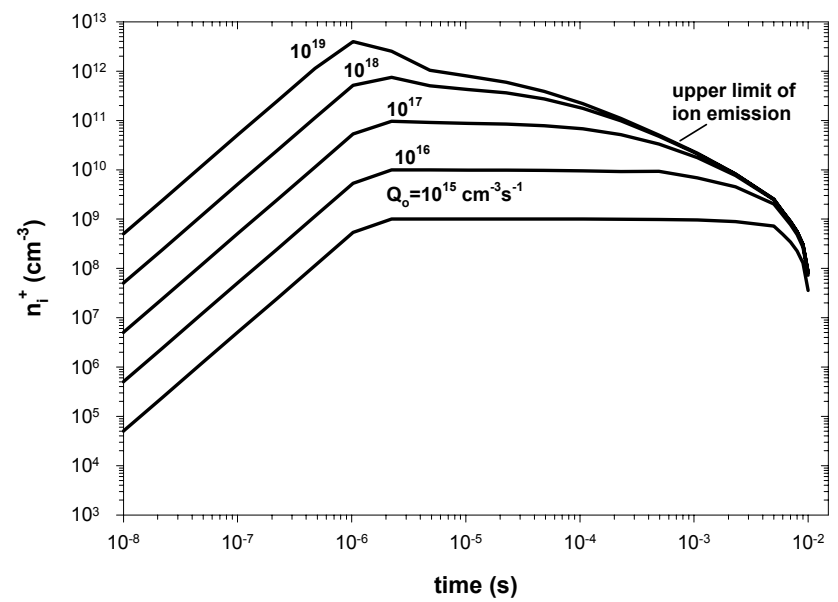

Fig. 4. Evolution of the concentration of positive ions in the engine, using different chemiionisation rates $Q_{o}$.

variation of $\tau_{\text {res }}$ from $\tau_{\text {res }}=5 \mathrm{~ms}$ to 2.5 and $10 \mathrm{~ms}$ leads to $n_{e x}=1.3 \times 10^{8}$ and $5.1 \times 10^{7} \mathrm{~cm}^{-3}$ with the model, while Eq. (12) gives $1.6 \times 10^{8}$ and $4.1 \times 10^{7} \mathrm{~cm}^{-3}$, respectively. Increasing the temperature at the combustor exit from $T_{c}=1200$ to $1500 \mathrm{~K}$ leads to $n_{e x}=1.55 \times 10^{8} \mathrm{~cm}^{-3}$ while Eq. (12) gives $2.0 \times 10^{8}$. Similarly, decreasing the nozzle exit temperature from $T_{e x}=650$ to $500 \mathrm{~K}$ leads to $n_{e x}=0.93 \times 10^{8} \mathrm{~cm}^{-3}$ instead of $1.07 \times 10^{8} \mathrm{~cm}^{-3}$. Finally, the model calculations confirm the dependence of $n_{e x}$ on the combustor pressure ratio $\pi_{c}$. The model results predict that the increase of $\pi_{c}$ from 20 to 30 leads to a decrease of ion emission from $n_{e x}=1.6 \times 10^{8}$ to $8.2 \times 10^{7} \mathrm{~cm}^{-3}$ while Eq. (12) gives $1.7 \times 10^{8}$ and $8.6 \times 10^{7}$, respectively. This diminution of $n_{e x}$ when $\pi_{c}$ is increased shows that the effect of pressure is larger on the recombination rates than on the production rates. One can conclude that, in the absence of soot particles, Eqs. (11)-(12) give a good estimate of the upper ion concentrations at the nozzle exit.

\subsection{CI concentration in the presence of soot particles}

Soot particles are now introduced with a monodisperse size and with a fixed number density $N_{s}=10^{8} \mathrm{~cm}^{-3}$. However, the radius a itself was varied from 10 to $30 \mathrm{~nm}$, leading to a soot particle loading in range $0.75-20.4 \mathrm{mg} / \mathrm{m}^{3}$ at the combustor exit and $0.05-1.3 \mathrm{mg} / \mathrm{m}^{3}$ at the engine exit (soot concentration at the nozzle exit is of the order of $10^{7} \mathrm{~cm}^{-3}$ ). These values are consistent with measurements for real aeroengines (Brocklehurst et al., 1997; Dopelheuer and Wahl, 2001). Note that the surface area of particles increases approximately by a factor of 2 when the radius changes from 20 to $30 \mathrm{~nm}$.

The calculations, shown in Fig. 5, have been performed with a maximal value of the chemiionisation rate $Q_{o}=$ $10^{17} \mathrm{~cm}^{-3} \mathrm{~s}^{-1}$ and with the the ion-ion recombination coefficients $k_{i i}$ taken from Beig and Brasseur (2000). The use of 


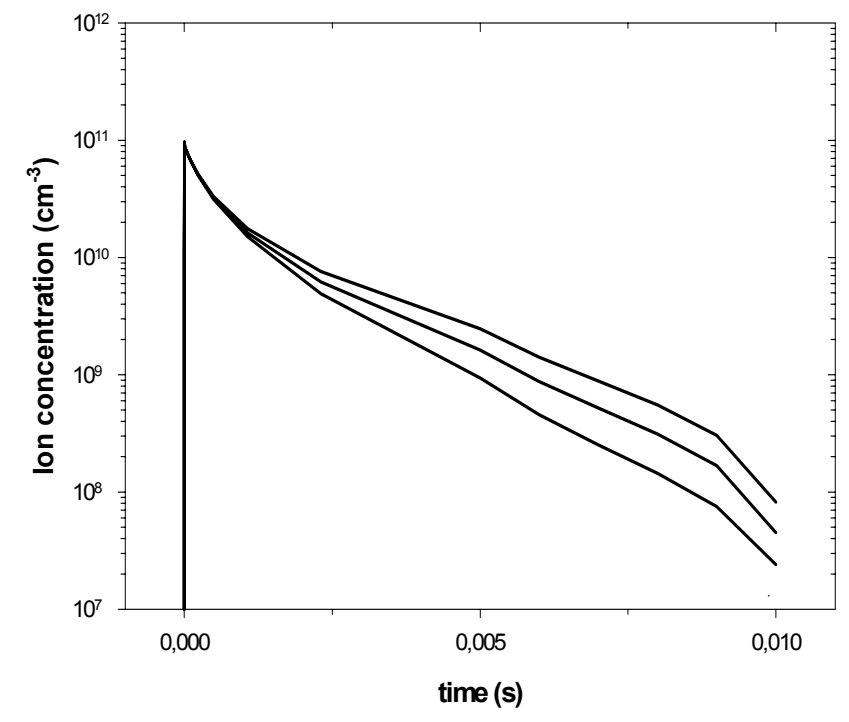

Fig. 5. Evolution of the concentration of positive ions in the engine, in the absence (upper curve) or presence of soot particles with a concentration $N_{s}=10^{8} \mathrm{~cm}^{-3}$ : intermediate curve, radius of soot particles $a=20 \mathrm{~nm}$, lower curve $a=30 \mathrm{~nm}$.

these coefficients lead to the maximum values of $n_{e x}$ at the nozzle exit. In Fig. 5, we compare the results obtained without soot particles $(a=0)$ with those obtained in the presence of soot particles with radius $a=20$ and $30 \mathrm{~nm}$. The exit concentration of chemi-ions (of one sign) varies from $n_{e x}=8.6 \times 10^{7} \mathrm{~cm}^{-3}$ in the absence of soot particles to $n_{e x}=4.5 \times 10^{7} \mathrm{~cm}^{-3}$ for $a=20 \mathrm{~nm}\left(E I_{i}=1.9 \times 10^{16}\right)$ and to $n_{e x}=2.6 \times 10^{7} \mathrm{~cm}^{-3}$ for $a=30 \mathrm{~nm}\left(E I_{i}=1.1 \times 10^{16}\right)$, i.e. the presence of soot particles decreases the chemi-ion concentration by a factor 1.8 to 3.2 compare to the situation without particles. It is also interesting to note that the ion concentrations decrease roughly by a factor 2 when the surface area of particles is doubled and that the interaction between ions and soot particles becomes important only for times larger than about $2 \mathrm{~ms}$, i.e. in the dilution zone of the combustor. At this time, soot particles are already formed and we can conclude that the inclusion of a detailed mechanism for soot formation will not change our estimate for the upper level of the CI emission.

The charge distribution of emitted soot particles, which can also be calculated by the model, is shown for the reference case in Fig. 6. It can be seen that most of the soot particles are charged, either at the combustor exit or nozzle exit. However, the charge distribution depends on the values assumed for the ion-ion recombination coefficient $k_{i i}$. If the compilation by Beig and Brasseur is used, the relative fractions of positively, negatively charged or neutral particles are $f_{s}^{+}=f_{s}^{-}=41.1 \%, f_{s}^{0}=17.8 \%$, respectively at the combustor exit and $f_{s}^{+}=f_{s}^{-}=39.1 \%, f_{s}^{0}=21.8 \%$ at the nozzle exit. If, on the contrary, Mätzing's compilation is used, a dissymmetry appears between positive and negative charges.

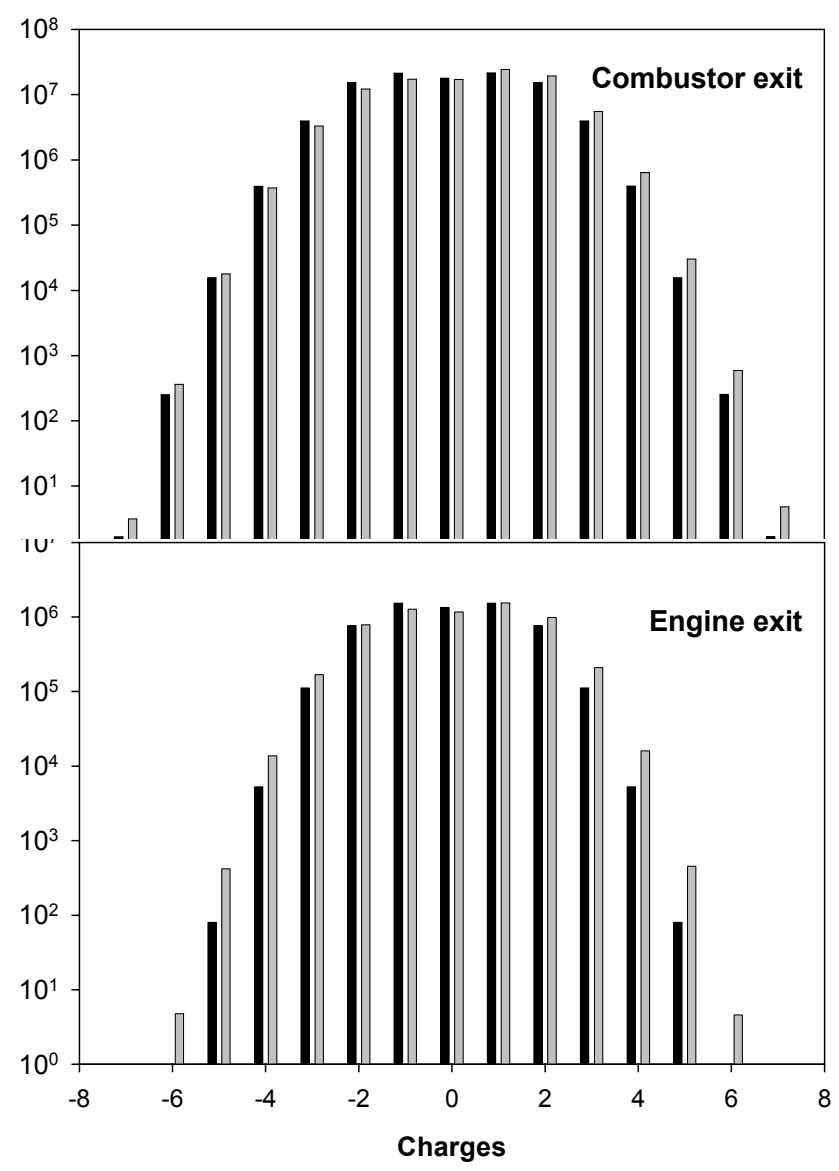

Fig. 6. Concentration of soot particles $\left(\mathrm{cm}^{-3}\right)$ as a function of their charge at the exit of the combustor and at the nozzle exit of the engine using two approximations for the ion-ion recombination coefficients $k_{i i}$. In black, distribution obtained with the compilation of Beig and Brasseur (2000), in gray distribution obtained with the compilation of Mätzing (1991).

In this case, $f_{s}^{+}=49.8 \%, f_{s}^{-}=33.2 \%, f_{s}^{0}=17.0 \%$ at the combustor exit and $f_{s}^{+}=44.7 \%, f_{s}^{-}=36.4 \%$, $f_{s}^{0}=18.9 \%$ at the nozzle exit. Soot particles are then, on the average positively charged, with a mean charge of the order of 0.13 elementary charges.

The excess of positive charges on soot particles may be compensated by some excess negative ions in the exhaust, to keep the total electro-neutrality. However the differences of mobility between gaseous ions and charged soot particles may lead to the electrization of some aircraft elements (Vatazhin et al., 1983).

\subsection{Application: comparison with on ground measure- ments}

Very few measurements of CI are available to verify our model. Arnold et al. (2000) measured the total CI concentration in the exhaust plume of the ATTAS aircraft on the 
ground. The ATTAS is a mid-sized jet aircraft equipped with two Rolls-Royce SNECMA M45H engines.

The measurements were performed just behind the hot potential core, at three distances from the nozzle exit in the exhaust plume: $d=1.39,2.19$ and $4.19 \mathrm{~m}$. The parameters needed for the calculations were taken as follows (Schumann et al., 2001): $P_{a}=1 \mathrm{~atm}, \pi_{c}=16.5, T_{e x}=683 \mathrm{~K}$, emission index of soot particles $E I_{S}=0.13 \mathrm{~g} / \mathrm{kg}$ (fuel) or $1.6 \times 10^{15}$ particles $/ \mathrm{kg}$ (fuel). Using $N_{f}=70, a \approx 22 \mathrm{~nm}$ one obtains $N_{s} \approx 10^{8} \mathrm{~cm}^{-3}$. The residence times in the combustor and post-combustor zone are $\tau_{\text {res }} \approx 3.8$ and $\tau_{e x} \approx 5.2 \mathrm{~ms}$, respectively. Since the volume of the combustion chamber also includes the primary zone which is not included in the model, (the volume of the primary zone is about $\leq 1 / 3$ of the total volume of the combustor), the residence time considered in the combustor was taken as $(2 / 3) \tau_{\text {res }}$ (Lefebvre, 1985; Kuznetsov, 1983). Unfortunately the temperature of the exhaust gases at the combustor exit is not known for the case of the ATTAS aircraft on the ground, but a simple calculation from a heat budget shows that in flight such a temperature is about $1155 \mathrm{~K}$ (Schumann et al., 2001). Calculations were then made for several values of $T_{c}$ in the range $1155-1500 \mathrm{~K}$. The calculations made with these parameters give, for the concentration of ions of one sign at the nozzle exit $n_{e x} \approx(0.8-2) \times 10^{8} \mathrm{~cm}^{-3}$ for $T_{c}$ in the range 1155$1500 \mathrm{~K}$. This leads to a total emission index for ion of both signs of $(2,2-5,4) \times 10^{16}$ ions $/ \mathrm{kg}$ (fuel). These results are in excellent agreement with those provided by the theoretical analysis (Sorokin and Mirabel, 2001) of the measurements made by Arnold et al. (2000).

\section{Summary and conclusion}

A numerical model has been developed to predict the formation and evolution of chemiions in an aircraft engine. The model includes the formation of primary electrons and positive ions by chemiionisation, electron attachment to neutral gas species, ion-ion recombination, interaction of electrons and ions, thermo-emission from the soot surfaces in the hightemperature region of the combustor. It also examines the interaction between emitted electrons, ions and soot surfaces leading to the charging of soot particles.

The model results, i.e. the concentration of chemiions at the combustor exit and at the nozzle exit of the engine depend directly on the ion-ion recombination rate, for which the data are scarce at the temperatures prevailing in a jet engine.

The interaction of ions with soot particles may lead to a $50 \%$ decrease of the exit ion concentration, compare to the situation without particles. A consequence of ion-soot interaction is that most of soot particles at the nozzle exit are charged and the concentration of neutral soot particles is only of the order of $20 \%$. The remaining fraction of the particles are charged, with an important fraction carrying up to 5-6 elementary charges.
Finally, for typical jet engines operated at ground conditions, taking into account the presence of particles, the $\mathrm{CI}$ emission index is in the range $E I_{i}=(2-5) \times 10^{16}$ ions of both signs per kg of fuel.

Acknowledgements. Support of this work by the European Community through contract G4RD-CT-2000-00207 (PARTEMIS) and by the INTAS project OPEN 2000-460 is gratefully acknowledged.

\section{References}

Arnold, F., Wohlfrom, K. H., Klemm, M. W., Schneider, J., Gollinger, K., Schumann, U., and Busen, R.: First gaseous ion composition measurements in the exhaust plume of a jet aircraft in flight: Implication for gaseous sulfuric acid, aerosols, and chemiions, Geophys. Res. Lett., 25, 2137-2140, 1998.

Arnold, F., Kiendler, A., Wiedemer, V., Aberle, S., Stilp, T., and Busen, R.: Chemiion concentration measurements in jet engine exhaust at the ground: Implications for ion chemistry and aerosol formation in the wake of a jet aircraft, Geophys. Res. Lett., 27, 1723-1726, 2000.

Ball R. T. and Howard, J. B.: Electric charge of carbon particles in flames, Thirteenth Symposium (International) on Combustion, 353-362, The Combustion Institute, 1971.

Bates, D. R.: Recombination of small ions in the troposphere and lower stratosphere, Planet Space Sci., 30, 101-108, 1982.

Bates, D. R.: Ion-ion recombination in an ambient gas, Adv. At. Mol. Phys., 20, 1-40, 1985.

Beig, G. and Brasseur, G. P.: Model of tropospheric ion composition: A first attempt, J. Geophys. Res., 105, 22 671-22 684, 2000.

Böhme, D. K.: Chemical ionization in flames, in: Ion molecular reactions, Plenum Press, N.Y., 323-343, 1972.

Böhme, D. K.: Experimental studies of positive ion chemistry with flow tube mass spectrometry: birth, evolution, and achievements in the 20th century, Int. J. Mass Spectrometry, 200, 97-136, 2000.

Brocklehurst, H. T., Priddin, C. H., and Moss, J. B.: Soot predictions within an aero gas turbine combustion chamber, American Society of Mechanical Engineers, 97-GT-148, June 1997.

Burtscher, H., Reis, A., and Schmidt-Ott, A.: Particle charge in combustion aerosols, J. Aerosol Sci., 17, 47-51, 1986.

Butler C. J. and Hayhurst, A. N.: Kinetics of dissociative recombination of $\mathrm{H}_{3} \mathrm{O}^{+}$ions with free electrons in premixed flames, $\mathrm{J}$. Chem. Soc. Faraday Trans., 92, 707-714, 1996.

Calcote, H. F.: Ion production and recombination in flames, Eight Symposium (Int.) on Combustion, 184-199, Williams and Wilkins, 1962.

Calcote, H. F. and Keil, D. G.: Ion-molecule reactions in sooting acetylene-oxygen flames, Comb. Flame, 74, 131-146, 1990.

Dopelheuer, A. and Wahl, C.: Determination of quantities and properties of aircraft engine generated soot, Air Pollution Research Report 74, Aviation, aerosols, contrails and cirrus clouds (A2C3), Proceedings of a European workshop, Frankfurt, Germany, pp. 91-94, July 2000.

Eraslan, A. N. and Brown, R. C.: Chemiionization and ionmolecule reactions in fuel-rich acetylene flames, Comb. Flames, 74, 19-37, 1988. 
Fahey, D. W., Keim, E.R., Woodbridge, E. L., et al.: In situ observations in aircraft exhaust plumes in the lower stratosphere at midlatitudes, J. Geophys. Res., 100, 3065-3074, 1995.

Fialkov, A. B.: Investigation on ions in flames, Prog. Energy Comb. Sci., 23, 399-528, 1997.

Frenzel, A. and Arnold, F.: Sulphuric acid cluster ion formation by jet engines: Implications for sulphuric acid formation and nucleation, in: On Impact from Aircraft and Spacecraft upon the Atmosphere, Proc. Intern. Scientific Coll., Köln 1994, DLR-Mitt. 94-06, 106-112, 1994.

Gerhardt P. and Homann, K. H.: Ions and charged soot particles in hydrocarbon flames III: negative ions in fuel-rich acethylene/oxygen flames, Ber. Bunsen-ges. Phys. Chem., 94, 10861096, 1990.

Green, J. A. and Sugden, T. M.: Some observation on the mechanism of ionization in flames containing hydrocarbons, Ninth Symposium (Int.) on Combustion, 607-621, Williams and Wilkins, 1963.

Goodings, J. M., Böhme, D. K., and Ng, C.-W.: Detailed ion chemistry in methane-oxygen flames. II. Negative ions, Comb. Flame, 36, 45-62, 1979.

Guo, J. and Goodings, J. M.: Recombination coefficients for $\mathrm{H}_{3} \mathrm{O}^{+}$ ions with electrons $\mathrm{e}^{-}$and with $\mathrm{Cl}^{-}, \mathrm{Br}^{-}$and $\mathrm{I}^{-}$at flame temperatures 1820-2400 K, Chem. Phys. Lett., 329, 393-398, 2000.

Hayhurst, A. N. and Kittelson, D. B.: The positive and negative ions in oxy-acetylene flames, Comb. Flame, 31, 37-51, 1978.

Hoppel W. A. and Frick, G. M.: Ion-aerosol attachment coefficients and the steady-state charge distribution on aerosols in a bipolar ion environment, Aerosol Sci. Techn., 5, 1-21, 1986.

Hu, D., Braun-Unkhoff, M., and Frank, P.: Early stage of soot formation at elevated pressures, Air Pollution Research Report 74, Aviation, aerosols, contrails and cirrus clouds (A2C3), Proceedings of a European workshop, Frankfurt, Germany, 85-90, July 2000.

IPCC: Intergovernmental Panel of Climate Change, Aviation and the Global Amosphere, (Eds) Penner, J., Lister, D., Griggs, D., Dokken, D., and McFarland, M., Cambridge University Press, Cambridge, U.K., 1999.

Kärcher, B., Yu, F., Schröder, F. P., and Turco, R. P.: Ultrafine aerosol particles in aircraft plumes: Analysis of growth mechanisms, Geophys. Res. Lett., 25, 2793-2796, 1998.

Kiendler, A., Aberle, S., and Arnold, F.: Positive ion chemistry in the exhaust plumes of an aircraft engine and a burner: investigations with a quadrupole ion trap mass spectrometer, Atmos. Environ., 34, 4787-4793, 2000a.

Kiendler, A., Aberle, S., and Arnold, F.: Negative chemiions formed in jet fuel combustion: New insights from jet engine and laboratory measurements using a novel quadrupole ion trap mass spectrometer apparatus, Atmos. Environ., 34, 2623-2632, $2000 \mathrm{~b}$.

Kiendler, A. and Arnold, F.: Improved composition measurements of negative chemiions in aircraft jet engine exhaust: unambiguous identification of sulphuric acid clustering via sulphurisotopes, Geophys. Res. Lett., submitted, 2001.

Kossyi, I. A., Kostinsky, A. Yu., Matveyev, A. A., and Silakov, V. P.: Kinetic scheme of the non-equilibrium discharge in nitrogen- oxygen mixtures, Plasma Sources Sci. Technol., 1, 207-220, 1992.

Kuznetsov V. R.: Nitric oxides formation in gas turbine combustors, Proc. of Central Institute of Aviation Motors, 1086, Moscow, 1983.

Lawton J.: Rates of charging of small thermo ionic particles in a space charge, Comb. Flame, 12, 534-540, 1968.

Lawton, J. and Weinberg, F.: Electrical aspects of combustion, Oxford Univ. Press, 1969.

Lefebvre A. H.: Gas turbine combustion, N.Y., McGraw-Hill, 1985.

Mattingly J. D., Heiser, W. H., and Daley, D. H.: Aircraft Engine Design, AIAA Education Series, N.Y., 1987.

Mätzing, H.: Chemical kinetics of flue gas cleaning by irradiation with electrons, Part II, Adv. Chem. Phys., 80, 315-359, 1991.

Natanson, G. L.: The theory of the charging of sub-micron aerosol particles by gaseous ions, Sov. J. Tech. Phys. (Engl. Transl.) 5, 538-551, 1960.

Onischuk, A. A, di Stasio, S., Baklanov, V., Karasev, V., Makhov, G. A., Vlasenko, A. L., Ankilov, A. N., and Panfilov, V. N.: Coulomb interactions in soot particle formation, J. Aerosol Sci, 32, S71, 2001

Pederson, T. and Brown, R. C.: Simulation of electric field effects in premixed methane flames, Comb. Flames, 94, 433-448, 1993.

Rapp, M.: Capture rates of electrons and positive ions by mesospheric aerosol particles, J. Aerosol. Sci., 31, 1367-1369, 2000.

Schumann, U., Arnold, F., Busen, R., Curties, J., Kaercher, B. Kiendler, A., Petzold, A., Schlager, H., Schroder, F., and Wohlfrom, K.-H.: Influence of fuel sulfur on the composition of aircraft exhaust plumes: The experiments SULFUR 1-7, J. Geophys. Res., submitted, 107, 2002.

Seinfeld, J. H. and Pandis, S. P.: Atmospheric chemistry and physics, N.Y., Wiley, 1998.

Smith, D. and Adams, N. G.: Ionic recombination in the stratosphere, Geophys. Res. Lett., 9, 1085-1087, 1982.

Sorokin, A. and Mirabel, P.: Ion recombination in aircraft exhaust plumes, Geophys. Res. Lett., 28, 955-958, 2001.

Starik, A. M., Savel'ev, A. M., Titova, N. S., and Schumann, U.: Modeling of sulfur gases and chemiions in aircraft engines, Aerosp. Sci. Techn., 6, 63-81, 2002.

Sudarev, A. V. and Antonovski, V. I.: Soot content in a gas turbine combustion chamber, Low Grade Fuels, 2, 36, 431-441, 1990.

Tremmel H. G. and Schumann, U.: Model simulations of fuel sulfur conversion efficiencies in an aircraft engine: Dependence on reaction rate constants and initial species mixing ratios, Aerosp. Sci. Techno., 3, 417-430, 1999.

Vatazhin, A. B., Grabovski, V. I., Likhter, V. A., and Shul'gin, V. I.: Electro-gas-dynamical flows, Nauka, Moscow, (in russian), 1983.

Yu, F. and Turco, R. P.: The role of ions in the formation and evolution of particles in aircraft plumes, Geophys. Res. Lett., 24, 1927-1930, 1997.

Yu, F. and Turco, R. P.: The formation and evolution of aerosols in stratospheric aircraft plumes: Numerical simulations and comparison with observations, J. Geophys. Res., 103, 25 915-25 934, 1998. 